\title{
BMJ open Protocol for an observation and implementation study investigating optimisation of the management of stroke and transient ischaemic attack (TIA)
}

James Peter Sheppard, ${ }^{1}$ Ruth Mary Mellor, ${ }^{1}$ Sheila Marie Bailey, ${ }^{1}$ Pelham Barton, ${ }^{2}$ Amunpreet Boyal, ${ }^{1}$ Sheila Greenfield, ${ }^{1}$ Sue Jowett, ${ }^{2}$ Jonathan Mant, ${ }^{3}$ Tom Quinn, ${ }^{4}$ Satinder Singh, ${ }^{1}$ Richard J McManus, ${ }^{5}$ on behalf of the BBC CLAHRC Investigators*

To cite: Sheppard JP, Mellor RM, Bailey SM, et al. Protocol for an observation and implementation study investigating optimisation of the management of stroke and transient ischaemic attack (TIA). BMJ Open 2012;2:e001430. doi:10. 1136/bmjopen-2012-001430

- Prepublication history for this paper is available online. To view these files please visit the journal online (http:// dx.doi.org/10.1136/ bmjopen-2012-001430).

*For author footnote see end of the article.

Received 4 May 2012

Accepted 11 May 2012

This final article is available for use under the terms of the Creative Commons Attribution Non-Commercial 2.0 Licence; see http://bmjopen.bmj.com

For numbered affiliations see end of article.

Correspondence to Professor Richard $J$ McManus; richard. mcmanus@phc.ox.ac.uk

\section{ABSTRACT}

Introduction: Patients benefit from early and intensive treatment in both acute ischaemic stroke and transient ischaemic attack. Recent audits of acute stroke/ transient ischaemic attack care suggest that although standards have improved, current services still fall short of optimal care. The aim of this study is to establish a database of patients accessing stroke services. Data will be collected and analysed to provide individualised feedback to healthcare professionals who can then use these findings to develop strategies for service improvement.

Methods and analysis: This longitudinal observational study will evolve with the ongoing findings from the research output. The project will consist of three phases: assessment of current practice, feedback of findings and evaluation of service change. Consecutive patients will be recruited from participating hospitals, and identifiable data will be collected to link records from the Primary Care, Secondary Care and Emergency Services. As this study focuses on observation of current practice, a sample size calculation is not deemed appropriate. Patients will be sent follow-up questionnaires examining quality of life at 3 and 12 months post-event. Qualitative interviews will examine the care pathway through the experiences of patients, their carers, healthcare personnel and commissioners. Collected data will be used in economic analyses, which will evaluate the impact of current care and service redesign on the NHS costs and patient outcomes (death and quality of life).

Ethics and dissemination: Ethical approval for this study has been obtained from the National Research Ethics Committee (reference; 09/H0716/71), and sitespecific R\&D approval has been acquired from the relevant NHS trusts. All findings will be presented at relevant healthcare/academic conferences and written up for publication in peer-reviewed journals. Results will be fed back to patients and participating trusts through a series of reports and presentations. These

\section{ARTICLE SUMMARY}

Article focus

- Optimising the management of stroke and transient ischaemic attack (TIA).

- Study protocol using a mixed-methods approach.

Key messages

- Stroke and TIA are not currently managed effectively across the care pathway.

- This project will collect patient data across the care pathway from multiple NHS trusts.

- A model of research, feedback and evaluation will be adopted.

Strengths and limitations of this study

- Combining data collection from multiple healthcare settings with economic evaluations will provide a unique insight into stroke and TIA management across the care pathway.

- The need to obtain informed consent from patients to allow data linkage may limit the completeness of the data.

will be used to facilitate discussions about service redesign and implementation.

\section{BACKGROUND}

Stroke is one of the leading causes of morbidity and mortality worldwide, with an estimated 5.7 million deaths and 50 million disability-adjusted life-years lost every year. ${ }^{1}$ To this end, stroke-related mortality is expected to rise by $37 \%$ in the next 20 years. ${ }^{1}$ Effective diagnosis and management of stroke and transient ischaemic attack (TIA) is therefore of importance.

It is now well recognised that people who have a stroke or TIA benefit from early 
intensive treatment: in acute ischaemic stroke, thrombolysis within $3 \mathrm{~h}$ of symptom onset results in improved outcomes $^{2}$ and has thus been recommended by the National Institute for Health and Clinical Excellence. ${ }^{3}$ Indeed, this has now been extended to $4.5 \mathrm{~h}$ following observational data suggesting benefit from thrombolysis past the original time window. ${ }^{4}$ Similarly, people having a TIA are at high risk of having a subsequent stroke; these risks are highest in the first few days following the event. ${ }^{5}$ There are several interventions, both medical and surgical, that can substantially reduce this risk of stroke following a TIA, and evidence that earlier intervention is better. ${ }^{6}$

To ensure that patients with stroke and TIA receive diagnosis and treatment quickly, national guidelines recommend that services be designed to include a combination of emergency referral, early brain imaging and thrombolysis in acute stroke and immediate referral for urgent specialist assessment and investigation in TIA. ${ }^{6} 7$ The National Sentinel Stroke Audit reveals that although standards have improved, current care still falls short of these aspirations: in 2010, only $5 \%$ of patients received thrombolysis for acute stroke. ${ }^{8}$ For TIA services, care has improved with specialist review following TIA occurring within 7 days in $97 \%$ of highrisk patients and $86 \%$ of low-risk patients. ${ }^{9}$ However, this still falls short of the $100 \%$ specified in clinical guidelines.

The National Sentinel Stroke Audit ${ }^{8}$ is a useful tool for assessing current hospital stroke services across the country. However, this includes a small proportion of the total patients and cannot assess the whole care pathway for patients with acute stroke and TIA. Pre- and postevent management in Primary Care and via Emergency Services may have a significant impact on stroke and other cardiovascular events, ${ }^{10}$ hence effective prehospital care is vital in achieving the standards set out in the National Stroke Strategy. ${ }^{7}$ Currently, it is not clear to what extent the interaction between services impacts patient care and outcomes.

The aim of this project is to identify barriers to effective treatments and model the impact of service change on patient outcomes and NHS costs using data collected from the Primary Care, Secondary Care and Emergency Services. In addition, qualitative interviews and focus groups will establish the view of patients, their carers, healthcare personnel and commissioners towards current stroke and TIA care.

This work is part of the National Institute for Health Research, Collaborations for Leadership in Applied Health Research and Care(CLAHRC) programme. The main remit of this funding stream is to close the current gap between research and clinical practice. ${ }^{11}{ }^{12}$ As a result, a unique aspect of this project will be to combine research findings with routinely collected data in economic models and provide feedback to healthcare professionals and commissioners, working with them to develop strategies for change. This project will result in more detailed information on stroke and TIA services than ever before along with specific plans for service development underpinned by reliable cost-effectiveness data. Evaluation will assess the gap between research and clinical practice and provide a model for future research into service improvement in the NHS.

\section{METHODS}

\section{Study aims/research questions}

The overriding aim of this study is to optimise the acute management of people with stroke and TIA in Birmingham through identification and breaking down of current barriers to timely and effective treatment. The project involves an iterative process beginning with observation of current practice. From this initial observation, the following research questions have been formulated:

1. How do stroke and TIA patients get to hospital and why do they choose these routes?

2. To what extent does prehospital and hyperacute hospital care impact the timeliness of subsequent treatment, especially thrombolysis?

3. Are risk factors for cardiovascular disease correctly measured and managed in Primary Care before and after stroke or TIA?

4. What impact would service redesign to increase the proportion of acute stroke patients receiving thrombolysis have on the cost-effectiveness of care and patient outcomes in terms of strokes averted and quality-adjusted life-years?

5. What are the queuing effects caused by intermittent TIA clinics and what impact would a move to clinic slots, 7 days a week, have on patient outcomes and cost-effectiveness?

6. What do patients (and their carers) see as positive or negative aspects of the acute stroke patient pathway?

7. How do patient perspectives differ from those of the healthcare personnel working in the stroke pathway?

These research questions will be answered using a mixed-methods approach, bringing together quantitative, qualitative and economic analyses. A major goal of the work is to integrate with the healthcare service in which the research is conducted, building lasting relationships that reduce the existing gaps between research and implementation. ${ }^{11}{ }^{12}$ Using this model will enable further research questions to be generated in conjunction with the healthcare providers, ensuring that they are timely and relevant.

\section{Study design}

This is a longitudinal observational study of stroke and TIA management throughout the care pathway. The study will employ the Plan-Do-Study-Act cycles of implementation and evaluation. ${ }^{13}$ This model is commonly used in quality improvement projects ${ }^{14-16}$ and will be adapted for this project into three phases: assessment of current practice (recruitment of study participants and data collection), feedback (reporting of research 
findings directly to service providers) and evaluation (of ongoing service change through further recruitment and data collection) (figure 1). Recruitment and collection of data relating to stroke and TIA services, respectively, will be staggered to ensure resources are used effectively.

\section{Ethical considerations}

Although this study primarily involves service evaluation, ethical approval is required to allow collection of patient identifiers and sending out of quality-of-life questionnaires. Therefore, full ethical approval has been obtained from the National Research Ethics Service Committee, London-Queen Square (reference; 09/ H0716/71) and site-specific R\&D approval has been acquired from the relevant NHS trusts. In addition, participating trusts have given approval for anonymised data from clinical audits to be used within the quantitative analyses in this project.

\section{Study population/recruitment procedure}

The study will take place within two hospital trusts (University Hospitals Birmingham NHS Foundation Trust and Heart of England NHS Foundation Trust) and the surrounding Primary Care Trusts (South Birmingham, Birmingham East and North, Solihull, Sandwell, Dudley, Heart of Birmingham Teaching, Warwickshire, Worcestershire). Additional data relating to patients who travelled to hospital via ambulance will be collected from the West Midlands Ambulance Service NHS Trust (figure 2).

Patients will be recruited from stroke wards and TIA clinics in participating hospital trusts. Eligible patients will be those thought to be having a stroke or TIA who present to a collaborating hospital trust and are under the care of a participating stroke consultant during the data collection period (figure 2). Only patients unwilling or unable to give informed consent (and where no consultee is available) will be excluded. Informed consent will be gained from all patients to allow collection of patient identifiers and completion of quality-oflife questionnaires. Where an individual is unable to provide informed consent due to lack of capacity, assent from an appropriate consultee will be sought.

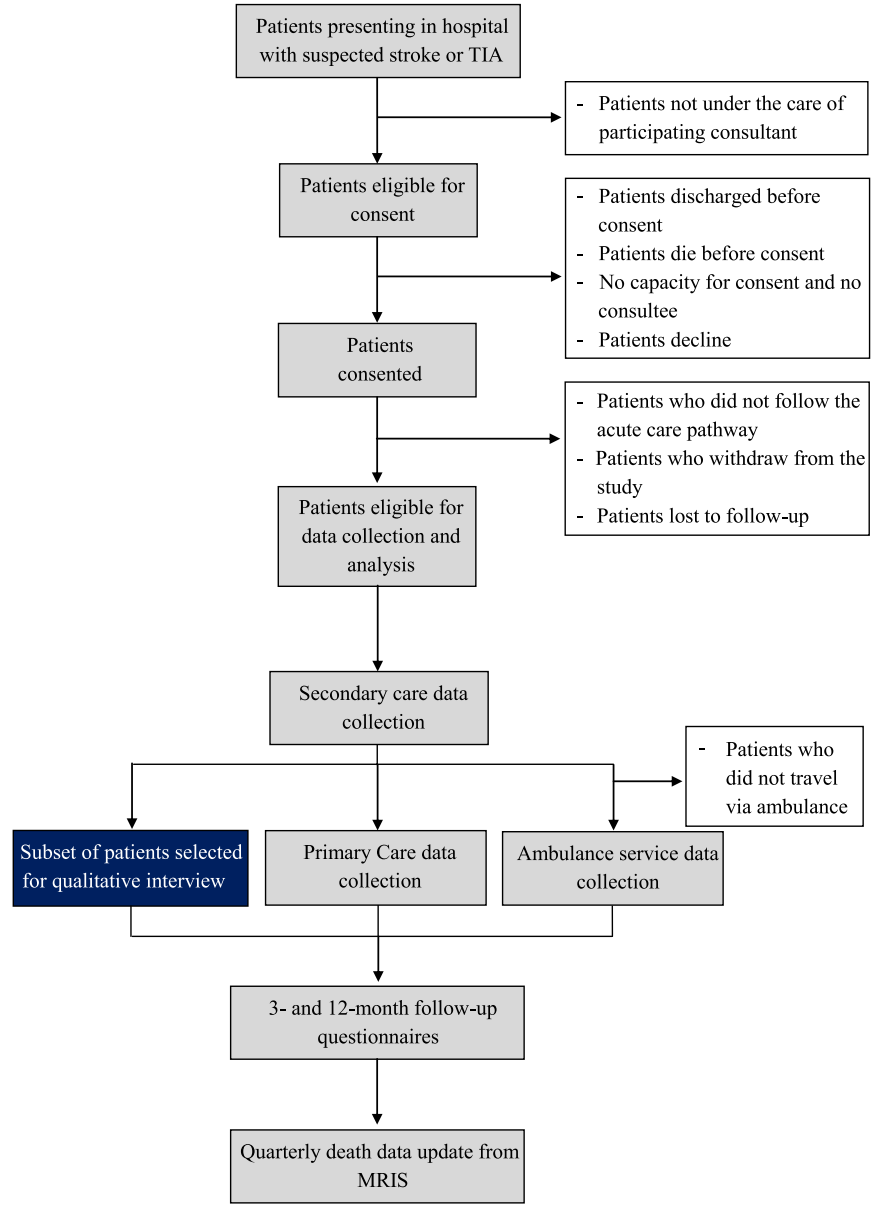

Figure 2 Flow diagram of patient recruitment and data collection during the study. MRIS, Medical Research Information Service; TIA, transient ischaemic attack.

Patients eligible for the qualitative component of the project will be selected from those recruited to the main study. Purposive sampling will be used in recruitment to ensure that a range of patient experiences is captured. Patients will be given the option of having their carer, friend or family member attend the interview with them and they can refer to them in order to help fill in the gaps in their accounts. All parties attending interviews will provide written informed consent.
Figure 1 Project timeline detailing phases and related activity throughout the project.

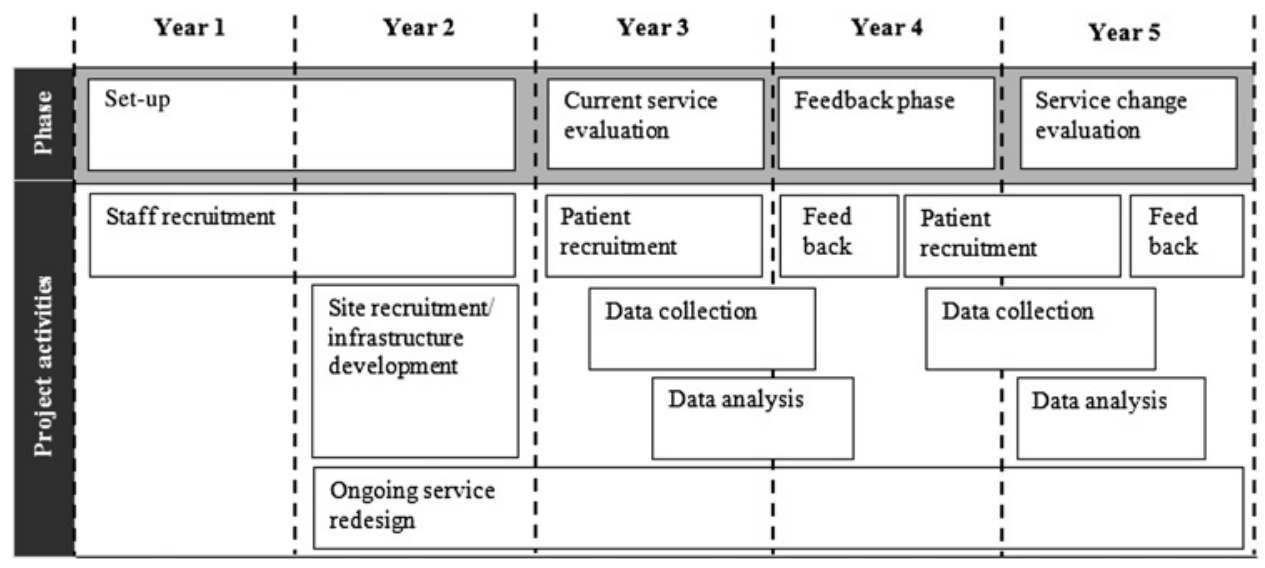


Healthcare personnel and commissioners will be interviewed, either on their own or in a focus group. Purposive sampling will be used to ensure recruitment of personnel across the care pathway, with study stakeholders acting as gatekeepers to recruit initial participants.

\section{Sample size}

No formal sample size calculation has been taken for this project. The nature of this study is that it is one of observation of current practice, and therefore, a sample size calculation was not deemed appropriate. However, based on validated data from both hospital trusts (2010-2011), approximately 400 patients with stroke and 350 patients with TIA attended each hospital each year. Based on our model of two 1-year data collection periods (the first being assessment of current practice and the second being an evaluation of practice change) (figure 1) and assuming around $75 \%$ recruitment of eligible patients, approximately 600 patients with stroke and 525 patients with TIA will be included per data collection period.
Within the qualitative component, interviews will be conducted with approximately 30 patients (some of whom will be accompanied by their carers). When 10 and 20 patients have been interviewed, a further theoretical sample will be sought, ${ }^{17}$ guided by the emerging data analysis in order to extend and challenge earlier data and interpretation and to test the integrity and credibility of the developing analysis. ${ }^{18}$ The proposed number of interviews will enable saturation of themes. $^{19}{ }^{20}$ Healthcare professionals and commissioners will be selected in a similar vein, with up to 30 per stakeholder group.

\section{Data collection}

Data related to the patient's present hospital admission/ clinic appointment and preceding stroke/TIA event will be collected retrospectively from hospital medical records (table 1 ). Patient identifiers will be collected to allow identification of patient records in other participating NHS trusts.

General practitioner surgeries from the participating Primary Care Trusts will be invited to participate in the

Table 1 Quantitative data collected from each healthcare setting

\begin{tabular}{|c|c|c|c|}
\hline Healthcare setting & Time period* & Data collected & Examples \\
\hline \multirow[t]{3}{*}{ Primary Care } & $\begin{array}{l}\text { Pre- and } \\
\text { post-stroke/ } \\
\text { TIA event }\end{array}$ & $\begin{array}{l}\text { Measurement of } \\
\text { cardiovascular } \\
\text { risk factors }\end{array}$ & $\begin{array}{l}\text { Blood pressure, cholesterol, smoking status, } \\
\text { absolute cardiovascular risk score }\end{array}$ \\
\hline & & $\begin{array}{l}\text { Management of } \\
\text { cardiovascular } \\
\text { risk factors }\end{array}$ & Antihypertensive and statin prescriptions \\
\hline & & Dates and times & $\begin{array}{l}\text { Relating to GP consultations, cardiovascular } \\
\text { risk factor measurements, prescriptions }\end{array}$ \\
\hline \multirow[t]{7}{*}{ Secondary Care } & $\begin{array}{l}\text { During stroke/ } \\
\text { TIA event }\end{array}$ & Patient identifiers & $\begin{array}{l}\text { NHS number, patient name, date of birth and } \\
\text { patient address }\end{array}$ \\
\hline & & Route to hospital & $\begin{array}{l}\text { Emergency ambulance, general practitioner } \\
\text { referral, self referral to the emergency department }\end{array}$ \\
\hline & & $\begin{array}{l}\text { Inhospital } \\
\text { investigations }\end{array}$ & CT scan, blood pressure, cholesterol \\
\hline & & Treatment given & Thrombolysis, carotid endarterectomy \\
\hline & & Dates and times & $\begin{array}{l}\text { Relating to onset of symptoms, arrival in hospital, } \\
\text { CT scan, first contact with medical/health } \\
\text { professionals, admission to hospital, discharge } \\
\text { from hospital, follow-up clinic appointment }\end{array}$ \\
\hline & & Discharge medication & Antihypertensive and statin prescriptions \\
\hline & & Final diagnosis & Stroke, TIA, stroke mimic \\
\hline Emergency & Pre-stroke/ & Presenting complaint & Suspected stroke, TIA, left-sided weakness \\
\hline \multirow[t]{4}{*}{ Services } & TIA event & Patient symptoms & Arm weakness, speech impediment, dizziness \\
\hline & & $\begin{array}{l}\text { Emergency service } \\
\text { investigations }\end{array}$ & $\begin{array}{l}\text { Face Arm Speech Test, blood pressure, } \\
\text { heart rate, Glasgow Coma Score }\end{array}$ \\
\hline & & $\begin{array}{l}\text { Medications } \\
\text { administered }\end{array}$ & Saline solution $(\mathrm{NaCl})$ \\
\hline & & Dates and times & $\begin{array}{l}\text { Relating to onset of symptoms, ambulance } \\
\text { dispatch, arrival at patient, departure for hospital, } \\
\text { arrival in the emergency department and } \\
\text { handover of patient care }\end{array}$ \\
\hline Medical Research & Post-stroke/ & Date and time & Of death \\
\hline Information Service & TIA event & Cause of death & As stated on death certificate \\
\hline
\end{tabular}


study, and data will be collected regarding Primary Care consultations, including primary and secondary prevention and outcome (table 1).

For those patients who travel to hospital via the Emergency Services, data will be extracted from the West Midlands Ambulance Service NHS Trust records. Relevant patient data will be identified using ambulance case and station numbers, extracted from hospital records. Data collected will include details of presenting complaints, patient symptoms, investigations conducted (eg, Face Arm Speech Test) and medications given (table 1). Timings from ambulance dispatch to arrival at hospital and handover will be acquired from the ambulance computer-aided dispatch system.

Additional anonymised data will be collected from all participating hospital trusts. These data will include demographics for all validated stroke admissions during each data collection period. This will be used to define the proportion of eligible patients successfully recruited to the study and whether these patients are representative of the general stroke population. Additional data regarding all scheduled TIA follow-up clinics will also be collected from both hospital sites for use in economic analyses.

Data from each NHS trust will be securely transferred into a bespoke web enabled SQL server database (Microsoft Corporation, Redmond, Washington, USA) stored securely at the host institution (University of Birmingham).

Qualitative data will be collected via in-depth interview or focus group. In-depth interviews will be used as they offer the most appropriate way to elicit people's beliefs and experiences. ${ }^{21}{ }^{22}$ Focus groups provide an opportunity for interaction between participants, allowing them to reflect on their own and others perspectives. ${ }^{23}$ Flexibility in data collection is required to enable as broad a range of people to participate as possible, for example, focus groups are more appropriate in some of the healthcare environments.

Interviews and focus groups will follow a topic guide, developed iteratively as the study progresses. ${ }^{24}$ Data will be collected from patients (and their carers) about their stroke and TIA experience and their treatment and care in relation to this. Healthcare personnel and commissioners will be asked about the stroke and TIA patient pathways, in particular, areas they think are good or that could be improved.

Following interviews and focus groups, the interviewer will write field notes, ${ }^{25}$ noting the context and 'feel' of the interview (eg, if there were any points at which the participant was uncomfortable). Non-verbal communication will also be recorded in this. These field notes will be used in conjunction with interview transcripts during data analysis.

\section{Follow-up}

Postal questionnaires will be sent to all recruited patients (who are still alive) at 3 and 12 months after the initial stroke/TIA event. These questionnaires will contain health status assessments, including the Modified Rankin Score, EQ-5D and the Stroke Impact Scale. Patients' vital status will be checked using the NHS Personal Demographics Service, 1 week prior to sending the questionnaire.

Details of all recruited patients will be sent to the Medical Research Information Service at the NHS Information Centre (Leeds, England). They will provide quarterly follow-up data on all-cause mortality for all patients in the study (table 1 ).

\section{DATA ANALYSIS AND DISSEMINATION \\ Epidemiological study}

Quantitative data from all trusts will be collated and analysed to assess existing barriers to effective treatment for stroke and TIA. Previous literature assessing barriers to effective acute stroke care have focused primarily on public awareness ${ }^{2627}$ and hospital care. ${ }^{28-30}$ The main focus of our analyses will be to use linked data from each patient to assess the impact of care across the clinical pathway (hence across clinical organisations), something that is not currently possible with routine clinical audits in the UK. ${ }^{8}$ Descriptive statistics will be used to define current practice, and logistic regression analyses will evaluate associations between identified barriers to care and other influencing factors.

Epidemiological findings will be used to inform proposed strategies for change in the economic analyses of the stroke and TIA care pathway. In addition, trustspecific findings will be reported back to relevant parties through a series of tailored reports and presentations. This dissemination will offer a unique opportunity to feedback findings between trusts and facilitate joined-up service provision.

\section{Economic modelling study}

In acute stroke, previous economic analyses have assessed the effects of thrombolysis against 'conservative treatment' (no thrombolysis). ${ }^{31-34}$ In the present study, we intend to compare current care (including thrombolysis) with 'change strategies' designed to increase thrombolysis rates. Following the feedback phase of the project (figure 1), we will use the same modelling approach to examine whether ongoing service change has been effective.

Through work previously commissioned by the West Midlands Strategic Health Authority, a mathematical model has been developed that compares current practice with service redesign. This decision tree model maps out the acute stroke care pathway, using a series of probabilities (derived from epidemiological data collected), which predicts the likelihood a patient will access a specific service or be given a type of treatment. The model will be used to evaluate the impact of treatment decisions on NHS costs and patient outcomes (death and quality of life). These costs will be derived from a combination of standard unit costs, NHS reference costs and previously published literature. ${ }^{31}{ }^{35}$ 
Health status data will be collected directly from patients using 3- and 12-month follow-up questionnaires and supplemented with published data. ${ }^{31}$

Our group has also previously developed a mathematical model, which aims to determine the optimum pattern of service provision for people presenting with a TIA or minor stroke. ${ }^{36}$ This discrete event simulation model examines the workload and cost implications of various methods of organising care. In the present study, the model will be used to track individuals who are occasionally competing for resources in a realistic representation of calendar time (the availability of these resources depends on time of day and day of week). This will allow estimation of the impact of redesigning TIA services on NHS costs and patient outcomes. Once again, the model will be based on real-life data collected from recruited patients and anonymised data from the hospital trusts.

Economic modelling is relevant in this situation as it allows comparison of different patterns of service provision in a systematic fashion where trial comparison would be impracticable. The findings of these studies will be fed back to participating trusts through reports and presentations. Specifically, service commissioners will be engaged, and these data will be central to future commissioning of stroke services across the participating Trusts.

\section{Qualitative study}

Qualitative methodologies offer the most appropriate way to elicit people's beliefs, knowledge and the meanings they ascribe to their experiences. ${ }^{21} 22$ In this study, these methodologies will be used to examine what barriers to service delivery, implementation and use, patients and healthcare professionals experience along the stroke and TIA care pathway.

Interview transcripts will be read and checked for accuracy and then entered into a computerised database using the NVivo software package (QSR International Pty Ltd, Doncaster, Victoria, Australia). Data analysis will be conducted using constant comparative analysis, with examination of deviant cases. ${ }^{37} 38$ Coding processes, including creating OSOPs, ${ }^{24}$ will identify emerging key categories and concepts from the participant data. These will be compared across interviews and time of data collection in order to capture the process of change. Concepts identified will further be compared against established concepts in the literature and will be integrated into themes providing a structure for presentation of findings. Researchers from a number of disciplines (sociology, public health, nursing and primary care) will be involved in the analysis, allowing for a range of insights to be gained. ${ }^{24}$ Other steps to ensure rigour will include: having two (or more) researchers independently code initial transcripts and then compare findings to formulate an initial coding frame.

Findings will be fed back to participating trusts in conjunction with epidemiological and economic modelling feedback. This qualitative element of the project will offer a unique insight to the overall study findings and facilitate service redesign, which is better tailored to patient and practitioner needs.

\section{CONCLUSIONS}

The CLAHRC Optimisation of the Management of Stroke and TIA project will build on previous work by describing current practice in stroke and TIA care ${ }^{89}$ and examine the potential effects of implementation of the National Stroke Strategy. ${ }^{7}$ By working together with multiple healthcare trusts, this study aims to improve patient care right across the stroke and TIA care pathway. Using a generalisable model, data collection, analysis, feedback and evaluation will be carried out within the life of this project. This model of research, feedback and evaluation will be assessed for its potential to set the foundations for how healthcare services are routinely examined and optimised in the future.

\section{Author affiliations}

${ }^{1}$ Department of Primary Care Clinical Sciences, University of Birmingham, Birmingham, UK

${ }^{2}$ Health Economics Unit, University of Birmingham, Birmingham, UK ${ }^{3}$ Department of Public Health and Primary Care, University of Cambridge, Cambridge, UK

${ }^{4}$ Faculty of Health and Medical Sciences, School of Health and Social Care, University of Surrey, Guildford, UK

${ }^{5}$ Department of Primary Care Health Sciences, University of Oxford, Oxford, UK Author footnote

*Birmingham and Black Country Collaborations for Leadership in Applied Health Research and Care investigators include: Peter Carr, Heart of England NHS Foundation Trust; Brin Helliwell, Lay member of Steering Group; Cristina Nand, Lay member of Steering Group; Norman Phillips, Lay member of Steering Group; David Sandler, Heart of England NHS Foundation Trust; Don Sims, University Hospitals Birmingham NHS Foundation Trust; Rob Scott, Birmingham and Midland Eye Centre; Matt Ward, West Midlands Ambulance Service NHS Trust.

Contributors RJMcM, JM, SJ and PB had the original idea, gained the funding and wrote the first draft with JPS and RMM. All authors subsequently refined the manuscript and approved the final version. RJMcM is the guarantor.

Funding The research was funded by and took place at the National Institute for Health Research (NIHR) Collaboration for Leadership in Applied Health Research and Care based in Birmingham and Black Country. RJMcM holds an NIHR Career Development Fellowship. The views and opinions expressed are those of the authors and do not necessarily reflect those of the NHS, NIHR or the Department of Health. The funders had no involvement in the study design, data collection, management of the project, data analysis, interpretation of data, writing of the article or the decision to submit the article for publication. The corresponding author (RJMcM) has ultimate authority over each of these activities.

\section{Competing interests None.}

Ethics approval Approval for this project has been obtained from the National Research Ethics Service Committee, London-Queen Square (reference; 09/H0716/71).

Provenance and peer review Not commissioned; internally peer reviewed.

\section{REFERENCES}

1. Strong $\mathrm{K}$, Mathers $\mathrm{C}$, Bonita R. Preventing stroke: saving lives around the world. Lancet Neurol 2007;6:182-7.

2. Wardlaw JM, Murray V, Berge E, et al. Thrombolysis for acute ischaemic stroke. Cochrane Database Syst Rev 2009;(4):CD000213.

3. Chung $\mathrm{H}$, Refoios $\mathrm{CR}$, Barnett D. Alteplase for the treatment of acute ischaemic stroke: NICE technology appraisal guidance. Heart 2007;93:1616-17. 
4. Wahlgren N, Ahmed N, Davalos A, et al. Thrombolysis with alteplase 3-4.5 $\mathrm{h}$ after acute ischaemic stroke (SITS-ISTR): an observational study. Lancet 2008;372:1303-9.

5. Rothwell PM, Giles MF, Flossmann E, et al. A simple score (ABCD) to identify individuals at high early risk of stroke after transient ischaemic attack. Lancet 2005;366:29-36.

6. National Institute for Health and Clinical Excellence (NICE). Diagnosis and Intial Management of Acute Stroke and Transient Ischemic Attack (TIA). NICE CG068. NICE Clinical Guideline. London: NICE, 2008.

7. Department of Health. National Stroke Strategy. London: Crown, 2007.

8. Henssge U, Hoffman A, Kavanagh S, et al. The National Sentinal Stroke Audit 2010. Round 7. London: Royal College of Physicians, 2011:1-74

9. The Intercollegiate Stroke Working Party. National Sentinal Stroke Audit-Organisation of Care 2010. Round 7. London: Royal College of Physicians, 2010.

10. McElduff $P$, Lyratzopoulos $\mathrm{G}$, Edwards $\mathrm{R}$, et al. Will changes in primary care improve health outcomes? Modelling the impact of financial incentives introduced to improve quality of care in the UK. Qual Saf Health Care 2004:13:191-7.

11. Black $\mathrm{N}$. The Cooksey review of UK health research funding. BMJ 2006;333:1231-2.

12. Cooksey D. A Review of UK Health Research Funding. London: The Stationery Office, 2006.

13. Langley GJ, Nolan KM, Nolan TW, et al. The Improvement Guide. A Practical Approach to Enhancing Organizational Performance. San Francisco, CA: Jossey-Bass, 1996.

14. Fortney J, Enderle M, McDougall S, et al. Implementation outcomes of evidence-based quality improvement for depression in VA community based outpatient clinics. Implement Sci 2012;7:30.

15. Koetsier A, van der Veer SN, Jager KJ, et al. Control charts in healthcare quality improvement. A systematic review on adherence to methodological criteria. Methods Inf Med 2012;51:189-98.

16. White $\mathrm{CM}$, Statile $\mathrm{AM}$, Conway $\mathrm{PH}$, et al. Utilizing improvement science methods to improve physician compliance with proper hand hygiene. Pediatrics 2012;129:e1042-50.

17. Glaser B, Strauss AL. The Discovery of Grounded Theory: Strategies for Qualitative Research. Chicago: Aldine, 1967.

18. Strauss AL, Corbin J. Basics of Qualitative Research, Grounded Theory Procedures. London: Sage, 1990.

19. Morse JM. Determining sample size. Qual Health Res 2000;10:3-5.

20. DePaulo P. Sample size for qualitative research. The risk of missing something important. Quirk's Marketing Research Review. 2000: Article No.636.

21. Denzin N, Lincoln Y. Entering the Field of Qualitative Research. Thousand Oaks: Sage, 1994.

22. Britten N. Qualitative interviews in medical research. BMJ 1995;311:251-3.
23. Finch $\mathrm{H}$, Lewis J. Focus groups. In: Ritchie J, Lewis J, eds. Qualitative Research Practice: A Guide for Social Science Students and Researchers. London: Sage, 2003:170-98.

24. Ziebland S, McPherson A. Making sense of qualitative data analysis: an introduction with illustrations from DIPEx (personal experiences of health and illness). Med Educ 2006:40:405-14.

25. Corbin J, Strauss A. Memos and diagrams. In: Corbin J, Strauss A eds. Basics of Qualitative Research 3e. London: Sage, 2008 117-41.

26. Hodgson C, Lindsay P, Rubini F. Can mass media influence emergency department visits for stroke? Stroke 2007;38:2115-22.

27. Yoon SS, Heller RF, Levi C, et al. Knowledge of stroke risk factors, warning symptoms, and treatment among an Australian urban population. Stroke 2001;32:1926-30.

28. Harraf F, Sharma AK, Brown MM, et al. A multicentre observational study of presentation and early assessment of acute stroke. BMJ 2002;325:17.

29. Kwan J, Hand P, Sandercock P. A systematic review of barriers to delivery of thrombolysis for acute stroke. Age Ageing 2004;33:116-21.

30. Lindsberg PJ, Happola O, Kallela M, et al. Door to thrombolysis: ER reorganization and reduced delays to acute stroke treatment. Neurology 2006;67:334-6.

31. Sandercock P, Berge E, Dennis M, et al. Cost-effectiveness of thrombolysis with recombinant tissue plasminogen activator for acute ischemic stroke assessed by a model based on UK NHS costs. Stroke 2004;35:1490-7.

32. Mar J, Begiristain JM, Arrazola A. Cost-effectiveness analysis of thrombolytic treatment for stroke. Cerebrovasc Dis 2005;20:193-200.

33. Ehlers L, Andersen G, Clausen LB, et al. Cost-effectiveness of intravenous thrombolysis with alteplase within a 3-hour window after acute ischemic stroke. Stroke 2007;38:85-9.

34. Araujo DV, Teich V, Passos RB, et al. Analysis of the costeffectiveness of thrombolysis with alteplase in stroke. Arq Bras Cardiol 2010;95:12-20.

35. Ward S, Lloyd JM, Pandor A, et al. A systematic review and economic evaluation of statins for the prevention of coronary events. Health Technol Assess 2007;11:1-160, iii-iv.

36. Mant J, Barton PM, Ryan RP, et al. What Is the Optimum Model of Service Delivery for Transient Ischaemic Attack? London: Report for the National Co-ordinating Centre for NHS Service Delivery and Organisation (NCCSDO), 2007.

37. Glaser BG, Strauss AL. The Constant Comparative Method of Qualitative Analysis. The Discovery of Grounded Theory: Strategies for Qualitative Research. New York: Aldine de Gruyter, 1999.

38. Green J, Britten N. Qualitative research and evidence based medicine. BMJ 1998;316:1230-2. 